\title{
WHAT IS 'DIGITAL DYNAMICS'?
}

\author{
DIGITAL DYNAMICS IN NORDIC CONTEMPORARY ART \\ EDITED BY TANYA TOFT AG
}

BRISTOL: INTELLECT, 2019. 368 PAGES

ISBN: 978-1783209484

The anthology Digital Dynamics in Nordic Contemporary Art, edited by Danish curator and scholar in media and digital art, Tanya Toft Ag, is in 2 parts: a section made up of so-called artist testimonials by contemporary Nordic artists, and a section of 15 mostly academic articles, many of which deal with art works or artistic practices by the contributors to the first section. In addition, Toft Ag has written the introductory and concluding chapters.

\section{WHAT IS DIGITAL DYNAMICS?}

What struck me first, when I read the book, was the title. What does it mean? What are 'digital dynamics'? Having read the introductory chapter, I am afraid I am not as wise, as I could perhaps have hoped for. When the book's editor for instance in her introduction to the anthology spells out what she is referring to with this notion, it is, at best, very fluffy. The term, we are told, "announces a certain trajectory conditioned by digital culture that restructures our socio-political and cultural life worlds as a process of change over time" (3), after which she continues with a series of vague propositions on what this might mean (the word 'might' constantly pops up alongside recurring suggestions that this has to do with something 'broader', 'deeper', 'more prominent', etc.). In other words, the pivotal concept of the book, digital dynamics, is defined in highly imprecise terms.

Toft Ag explicitly states two agendas with the book. Firstly, she wants "to examine art's changing trajectories, meanings and roles - or 'genres' - in our contemporary condition influenced by the digital” (ibid.). This also includes how art might critically participate in "shaping our future societies" (ix), which she later, in her own chapter in section 2, ascribes to the fact that art is now composed of the same (digital) materiality as the rest of society and can thus act as "a kind of Trojan horse with implicit differential modes of resistance” (271). I would, however, argue, that this 
could also have been said about visual art under the visual culture of the society of the spectacle (especially since this argument has, in fact, often been made back in the day when it was visual culture that was in vogue, rather than the digital). In this sense, the often quite grandiose claims concerning art's political potentials as sometimes pertaining in particular to artistic practices of today come across as a bit historically uninformed.

Secondly, the book is also about getting the gatekeepers of the Nordic art scene up to date on digital contemporary art, hereby subtly implying that they presently are not (and perhaps rightly so!). Hence, the agenda of the book is, of course, also quite artcentric, that is: it is about what should be included as art and how it should be appreciated. In other words, borrowed from the sociology of art (for instance Bourdieu), the book is also very much about positioning oneself, or a specific genre, within the field or game of art (albeit with due reference to the importance and value of art to society at large); about carving out a new subfield within the field of art.

So, is it an anthology about internet or computer-based art in the contemporary Nordic setting? Obviously not. For instance, many of the book's chapters only brush upon the digital - sometimes just through applying theory, that has been conceptualised in relation to digital technologies and culture, on artistic practices that are not that digital at all. In fact, a recurring argument throughout the book is that today all artistic practices (perhaps even all our everyday practices in toto) are intimately entangled with digital technologies and culture.

In this sense, the book is simultaneously about "how contemporary art is changing in the era of the digital" and how the digital paves "new roads for art's enquiry and role in society" (vii). This, of course, also includes the practical and cultural enmeshment of digital technologies within those aspects of society that is not part of the spheres of art (or artistic practices), but this is less the topic of this anthology. Nonetheless, the interest is mostly on how the proliferation of digital technologies and culture influences art, its categories, notions, practices, objects, actors/actants, institutions, etc.

\section{WHY NORDIC?}

Another question that emerges when reading the book is: why 'Nordic'? Why this particular focus? Especially given the fact that both 'digital' and 'contemporary art' are categories which fundamentally challenge, perhaps even defy, the whole idea 
of regionality and locality in general. This is also discussed by Toft Ag herself, who argues-this time more convincinglythat especially the Nordic Welfare States, based on different variations of somewhat more collectivity-oriented models of citizenship are particularly interesting backdrops to the study of contemporary artistic practices, especially as these become increasingly enmeshed in digital technologies that are simultaneously based on ideas of interactivity, collaboration, cocreation and sharing (open-source, Do It With Others, etc.) and increasing isolation both physically and mentally (personalisation, surrounded by relevance, filter bubbles, echo chambers, etc.).

Yet, convincing as this might be on the abstract level, it does seem to have left some of the authors in this volume with quite a task of bringing the issue they are discussing and analysing in their individual contributions on par with the Nordic agenda of the collection. Hence, occasionally quite odd discussions pop up that tries to relate the quite diverse-and often very interesting, I should add-articles to the overall theme of the anthology. At times, this functions quite well as unexpected plot turns, or as truly transdisciplinary feats. At other times it simply seems misplaced or uncalled for.

\section{WHAT'S GOOD?}

These problems, however, should not divert from the fact, that a lot of the analytical articles in section 2 of the book are quite good and solid. This includes fairly short chapters from Jonathan Habib Engqvist, Jamie Allen \& Bernhard Garnicnig, Laura Beloff, Mette-Marie Zacher Sørensen, Morten Søndergaard and Stahl Stenslie, just to mention some of them. These chapters in section 2 are worthwhile because they deal with interesting artistic practices, in part because they are well-written. That being said, it does seem a bit strange that most of the cases are not all that recent, especially given the explicit emphasis on contemporaneity as well as the rapid speed of development within digital technologies and cultures.

The first section in the book, Artist testimonials, is also quite interesting. Here, a selection of Nordic artists have been asked a series of questions related to the following issues: (1) On being an artist with the digital; (2) On digital tools, methods and research processes; (3) On materiality and behaviour in digital art; (4) On Art between forms and fields; (5) On perception and art's experience; (6) On Nordic aesthetic conditions and identification; (7) On participatory practices and collaboration; (8) On art and society; 
(9) On (alternative, urban and public) spaces for digital art; (10) On art and representation; (11) On art, nature and environment.

The intention of this, according to Toft Ag, was to "reveal how the digital dynamics that currently change our world simultaneously change the inquiries and forms of contemporary art, by changing the conditions, tools and imaginations of artists' practices” (33). Is there, one might ask, a technological determinism lurking behind this? It certainly seems so, albeit perhaps one that is not full-blown, since art is simultaneously endowed with both great powers and enormous responsibilities as it "participates in (re)designing technological interfaces and architectures, disrupting our media landscapes and use of social networks, or intervening in infrastructures for networked processes of democratic participation” (267). Grand claims which would, of course, have seemed less inflated if it had been argued from cases of this happening, rather than on the basis of artists' statements about their own artistic practice (or about the potential of art in general).

Still, these questions and answers do deal with a certain pressing problem, scholars addressing the use of new digital technologies in productive practices always seem to face, namely: how to inquire the impact of technologies that are in the process of receding into the background, that is, of becoming part of the everyday workflows and routines of artistic production-or becoming black-boxed. ${ }^{1}$

The merit of the artist testimonies initiated and assembled by Toft Ag is that they do in fact supply the reader with insights into the intermingling of new technologies and human practices-or at least, they do so, if we also include the discussions in the more analytical section 2 . So, even though there certainly still is some truth to the dictum, that if you-especially in a more hermeneutic tradition-want to know about the meaning of specific art works, the last ones you would want to ask are the artists themselves, asking this kind of questions is not without some merit when you more specifically want to know more about the entanglement of specific technologies and artistic processes (especially if you do not intend to do field work or observations). To this end, this collection of artists' statements could function as a valuable resource to future inquiry.

Jan Løhmann Stephensen

1

Cf. Bruno Latour, Reassembling the Social: An Introduction to Actor-Network Theory (Oxford: Oxford University Press, 2005): 79-82. 